\title{
Crime and Punishment with Habit Formation
}

\author{
Vladimir Kühl Teles* Joaquim P. Andrade ${ }^{\dagger}$
}

18th July 2005

Área da ANPEC: Área 09 - Microeconomia, Métodos Quatitativos e Finanças.

\begin{abstract}
Moral concepts affect crime supply. This idea is modelled assuming that illegal activities is habit forming. We introduce habits in a intertemporal general equilibrium framework to illegal activities and compare its outcomes with a model without habit formation. The findings are that habit (i) reduces the crime level; (ii) reduces the marginal effect of illegal activities return on crime; (iii) reduces the efficacy of punishment.
\end{abstract}

Key-Words: Crime, Habit formation, Punishment.

JEL Class: K42, K14.

\section{Resumo}

Aspectos morais afetam a oferta de crime. Essa idéia é modelada assumindo que atividades ilegais são formadoras de hábitos. Nós introduzimos tal hipótese em um modelo de equilíbrio geral intertemporal de atividades ilegais, e comparamos os resultados com o modelo sem formação de hábito. Os resultados são que o hábito (i) reduz o nível de crime; (ii) reduz o efeito marginal dos retornos das atividades ilegais sobre o crime; (iii) reduz a eficácia da punição.

Palavras-Chave: Crime, Castigo, Formação de Hábito.

\footnotetext{
*Fundação Getúlio Vargas, Escola de Economia de São Paulo (EESP-FGV), vkteles@ @gvsp.br

†Universidade de Brasília, jandrade@unb.br
} 


\section{Crime and Punishment with Habit Formation}

\section{Introduction}

In the seminal paper of Becker and Murphy (1988) habit was included in the utility function to describe consumption behavior of harmful goods, notably drugs. In the present paper we merge the Becker and Murphy insight about this link between illegal behavior and habit with the traditional crime and punishment approach due to Becker (1968) in a general equilibrium framework.

The existence of habit formation due to factors such as social interactions may affect the behavior of agents in crime supply. Factors such as culture or religion provide social incentives that may induce habits in illegal activities. For example, surveys in Britain and the United States have indicated that at least a third of the citizens in both countries believe that religion provides a sociocultural and/or spiritual foundation for curtailing criminal behavior (Banks, Maloney and Wittrock, 1975; Jensen, 1981). Ellis and Peterson (1996) find that more religious countries have lower crime rates than less religious countries, at least regarding property crimes, using data from 13 industrial nations.

On the other hand Gaviria (2000) demonstrates, using a myriad empirical evidence — both statistical and anecdotal — that the daily contact of youth with criminal adults and criminal peers results in the erosion of morals and hence in a greater predisposition toward crime.

The insight that through the process of habit formation, one's own past decisions might influence the utility yielded by current decisions is hardly new; see, for example, Pareto (1897) and Marshall (1898).

In fact the habit formation hypothesis has been applied in many issues such as endogenous growth models (Carroll et al, 2000), cyclical consumption (Dockner and Feichtinger, 1993), aggregate savings (Alessie and Lusardi, 1997), money and growth (Faria, 2001), environment (Ono, 2002), fiscal policy (Burnside et al, 2004) and monetary policy (McCallum and Nelson,1999, Amato and Laubach, 2004), to mention a few. All these papers introduce habit in consumption. Nonetheless, Faria and LeónLedesma (2004) uses habits in number of hours worked to study labor supply. In fact, it is not only in consumption that habits may occur. Becker and Murphy (1988, p. 695), for example, explain that: "Not only cigarettes, alcoholic beverages, and cocaine are obviously addictive, but many other goods and activities have addictive aspects".

In this paper we assume that social incentives create an ethic that affects the number of hours allocated to criminal activities by a representative agent. This is modelled by assuming that crime is habit forming. The idea is quite intuitive: past crime forms a stock of habits that affect agents' disposition towards present crime.

This paper is organized as follows. Section 2 develops the model, characterizes equilibrium and shows the main result. Section 3 provides concluding remarks. 


\section{The Model}

While agents are stimulated to engage in criminal activities according to the expected positive returns, they are also subject to the effects of crime, with loss in income. According to this idea, we may argue that the total expected income $(Y)$ of a representative agent of this economy will be given by (1).

$$
\pi P+(1-\pi)[f(k, o)(1+\phi(o, \bar{o}))]
$$

where

$$
\phi(o, \bar{o}) \begin{cases}=0, & \text { if } o=\bar{o} \\ >0, & \text { if } o>\bar{o} \\ <0, & \text { if } o<\bar{o}\end{cases}
$$

Thus, $f(k, o)$ represents the production function, where $k$ is the capital stock and $o$ the number of hours spent on criminal activity. On the other hand, $\phi(o, \bar{o})$ represents the net income function of the criminal activity, where the agent chooses the number of hours that will be dedicated to crime, when faced with the average number of hours of the other agents, $\bar{o}$. This type of function is commonly used in illicit activity models such as in Ehrlich and Lui (1999) and Teles (2004). Complementarily, $\pi$ is the probability of punishment, and $P$ is the payoff of the punishment. In fact, $P$ may represent the consumption supplied for criminals by the society in prisons, for example. (see Fender, 1999).

The production function may be represented by,

$$
f(k, o)=A k^{\beta}(1-o)^{1-\beta}
$$

where agents devotes the fraction $(1-o)$ of his non-leisure time to current production, $A$ is the level of technology, and $\beta$ is the capital-share.

If we consider that criminal activity (o) directly affects the well-being of an agent, and if we incorporate this in his utility function, and that the individual cares not only about consumption $(c)$ and the instantaneous flow of offenses $(o)$, but also takes into account his past criminal activities, captured by his stock of habits $(h)$, then the instantaneous isoelastic utility function proposed by Abel (1990) is adapted to introduce $o$ :

$$
U(c, o, h)=\frac{\left[\left(o / h^{\gamma}\right)^{\alpha} c^{1-\alpha}\right]^{1-\sigma}-1}{1-\sigma}
$$

where $\alpha$ is a positive parameter that lies in the unitary interval, $\sigma$ is the coefficient of relative risk aversion, and $\gamma \in[0,1)$ indexes the importance of habits. If $\gamma=0$, then habit stock has no relevance, and the utility function reduces to the traditional case. While if $\gamma=1$, crime relative to habit stock is very important. 
Following Carroll et al. (2000) it is assumed that the stock of habits is a weighted average of past offenses. The stock of habits evolves according to:

$$
\dot{h}=v(o-h)
$$

where $v$ is a positive parameter determining the relative weights of offenses at different times. The smaller is $v$, the less important is offenses in the recent past.

The individual maximizes a discounted, infinite stream of utility:

$$
\begin{gathered}
\operatorname{Max}_{c, o} \int_{0}^{\infty} U(c, o, h) e^{-\rho t} d t \\
\dot{k}=Y-c-P \\
\dot{h}=v(o-h)
\end{gathered}
$$

By substituting (1) and (3) in (5) and solving the problem, and applying the equilibrium condition $o=\bar{o}$, the following first-order conditions are obtained,

$$
\begin{gathered}
\lambda_{k}=\left[\left(\frac{o}{h^{\gamma}}\right)^{\alpha} c^{1-\alpha}\right]^{-\sigma}\left[\left(\frac{o}{h^{\gamma}}\right)^{\alpha}(1-\alpha) c^{1-\alpha}\right] \\
-v \lambda_{h}=\left[\left(\frac{o}{h^{\gamma}}\right)^{\alpha} c^{1-\alpha}\right]^{-\sigma}\left[\alpha \frac{o^{\alpha-1}}{h^{\gamma \alpha}} c^{1-\alpha}\right]+\lambda_{k}\left\{(1-\pi) f_{o}+f \phi_{o}\right\} \\
\frac{\dot{\lambda}_{k}}{\lambda_{k}}=\rho-\left\{(1-\pi) f_{k}\right\} \\
\dot{\lambda}_{h}=\rho \lambda_{h}-\left[\left(\frac{o}{h^{\gamma}}\right)^{\alpha} c^{1-\alpha}\right]^{-\sigma}\left[-\gamma \alpha\left(\frac{o^{\alpha}}{h^{\alpha \gamma-1}}\right) c^{1-\alpha}\right]+\lambda_{h} v
\end{gathered}
$$

where $\lambda_{k}$ and $\lambda_{h}$ are the co-state variables of $k$ and $h$ respectively.

By substituting (6) in (7), and then this result in (9) and considering that in this model's steady-state the per capita variables remain constant, meaning that the shadowprice of capital and habits remains constant, we will have that the following equations establishes the steady-state condition.

$$
\begin{gathered}
\rho=\left\{(1-\pi) f_{k}\right\} \\
\rho=\frac{h \gamma \alpha}{\left(\frac{\alpha}{o}\right)+(1-\alpha)\left[(1-\pi) f_{o}+f \phi_{o}\right]} \\
\pi P+(1-\pi) f=c+P \\
o=h
\end{gathered}
$$

Using the production function (3) in this system it is possible to study the effects of habit formation on crime, according to what is listed in propositions 1 to 3 . 
Proposition 1 The importance of habit to the agent has a negative impact on his decision in crime practice if $\phi_{o}>0$ and $\phi_{o o}<0$.

Proof: Solving the system (10)-(13), using (3) and applying the implicit function theorem to result we obtain that,

$$
\frac{d o}{d \gamma}=\frac{o \alpha}{\rho\left\{\left[(1-o) \phi_{o o}-\phi_{o}\right](1-\alpha) A\left(\frac{(1-\pi) \beta A}{\rho}\right)^{\frac{\beta}{1-\beta}}-\frac{\alpha}{o^{2}}-\frac{\gamma \alpha}{\rho}\right\}}
$$

Since $\phi_{o}>0$ and $\phi_{o o}<0$ the relation $\frac{d o}{d \gamma}$ is negative.

Proposition 2 The importance of habit to the agent reduces the effect of crime return on his decision in crime practice.

Proof: The proof follows immediately from equation (14), where the marginal return of crime $\left(\phi_{o}\right)$ has a negative relationship with $|d o / d \gamma|$.

Proposition 3 The importance of habit reduces the efficacy of punishment

Proof: Solving the system (10)-(13), using (3) and applying the implicit function theorem to result we obtain that,

$$
\frac{d o}{d \pi}=\frac{\left\{(1-\alpha) A\left[\frac{(1-\pi) \beta A}{\rho}\right]^{\frac{\beta}{1-\beta}}\right\}\left\{\frac{A \beta^{2}}{(1-\beta) \rho}\left[\frac{(1-\pi) \beta A}{\rho}\right]^{-1}\left[(1-o) \phi_{o}-(1-\pi)(1-\beta)\right]+(1-\beta)\right\}}{\left\{\frac{\gamma \alpha}{\rho}+\frac{\alpha}{o^{2}}+(1-\alpha) A\left[\frac{(1-\pi) \beta A}{\rho}\right]^{\frac{\beta}{1-\beta}}\left[\phi_{o}-(1-o) \phi_{o o}\right]\right\}}
$$

where the importance of habit $(\gamma)$ has a negative relationship with $|d o / d \pi|$.

Propositions 1 and 2 state that when habit has a strong weight in the utility function the agent will practice less crime and the returns to crime become less important in his decision, respectively. These propositions are important because they lay the foundation to better understanding the lack of rationality which is frequently involved in criminality even in those cases in which the agent chooses not to engage in illicit activities, in spite of being more rational to do so.

Proposition 3 shows that an agent that attributes a strong weight to habit formation in his or her utility function cares less about the chances of being punished. This proposition corroborates that habit formation reduces the rationality of crime behavior and punishment loses its efficacy. This result is fundamental in the analysis of policies aimed at combating crime, since it becomes clear that under certain conditions investment in punishment may not be the most effective form of deterring crime. 


\section{Conclusion}

The tradition of the models addressing the economics of crime defines the decision of an agent participating in an illicit activity as a rational one, since it is an economic decision in which the benefits and costs of crime are weighted along with the alternatives. (Fender, 1999). From this perspective, this study has introduced habit in an intertemporal general equilibrium framework and demonstrates that habit reduces the rationality of crime, since both the returns to crime and punishment play a less important role in the agent's decision to engage in crime.

Comparing these results with the traditional result due to Becker and Murphy (1988), that built a model of drugs consumption with habit formation some considerations may be due. In Becker and Murphy framework, an increase in permanent punishment implies an increase on price of drugs, and, consequently, a decrease on its long run demand. Thus, the drugs traffic will fall, as crime related. In our model, where another type of crime (property crime)is considered, this relationship will not occur. If the punishment rises, the effects on crime level may not change significantly, as demonstrated in proposition 3.

Considering education programs, Becker and Murphy argues that greater efforts to educate the population on the harms of the use of drugs may not offset the effects of the reduction on dugs price on the long run. Contrarily, we demonstrate that education policies may be important to break increases on long run crime level if it is able to build an ethics pattern to avoid illegal activities. Summarily what this paper shows is that different kinds of crime may have opposite forms of combat, and the theoretical dynamic path of crime will change drastically if we consider habit formation in alternative ways.

\section{References}

[1] Alessie, R. and A. Lusardi (1997) Consumption, saving and habit formation, Economics Letters 55, 103-108.

[2] Amato, J. and Laubach, T. (2004) Implications of habit formation for optimal monetary policy. Journal of Monetary Economics 51 p. 305-325.

[3] Banks, C., Maloney, E. and Wittrock, H. (1975). Public attitudes toward crime and the penal system. British Journal of Criminology, 15. 228-240.

[4] Becker, G. (1968) "Crime and Punishment: An Economic Approach" The Journal of Political Economy, 76:2, 169-217.

[5] Becker, G.S. and K.M. Murphy (1988) A theory of rational addiction, The Journal of Political Economy 96, 675-700. 
[6] Burnside, C., Eichenbaum, M. and Fisher, J. (2004) Fiscal shocks and their consequences. Journal of Economic Theory 115,p. 89-117 5

[7] Dockner, E.J. and G. Feichtinger (1993) Cyclical consumption patterns and rational addiction, American Economic Review 83, 256-263.

[8] Ehrlich, I., Lui, F. (1999) "Bureaucratic Corruption and Endogenous Economic Growth" The Journal of Political Economy, Vol. 107, No. 6, Part 2: Symposium on the Economic Analysis of Social Behavior in Honor of Gary S. Becker. (Dec., 1999), pp. S270-S293.

[9] Ellis, L.; Peterson, J. (1996) Crime and religion: An international comparison among thirteen industrial nations. Personality and Individual Differences, Volume 20, Issue 6, June 1996, Pages 761-768.

[10] Faria, J.R. (2001) Habit formation in a monetary growth model, Economics Letters $73,51-55$.

[11] Faria, J.R. and León-Ledesma, M. (2004). Habit formation, working habits and technological progress. Manchester School, 72, 403-413.

[12] Fender, J. (1999) "A general equilibrium model of crime and punishment" Journal of Economic Behavior and Organization, Vol. 39 (1999) 437-453.

[13] Gaviria, A. (2000) Increasing returns and the evolution of violent crime: the case of Colombia. Journal of Development Economics. Vol. 61, 1-25.

[14] Jensen, G. (1981). Sociology of delinquency: Current issues. London: Sage.

[15] Marshall, A. (1898) Principles of Economics, 8th Ed. New York:Macmillan, 1898.

[16] McCallum, B. and Nelson, E. (1999) Nominal income targeting in an openeconomy optimizing model. Journal of Monetary Economics, 43, (1999) 553578.

[17] Ono, T. (2002) Is habitual consumption harmful to the environment? Economics Bulletin, Vol. 17, No. 1 pp. 1-10.

[18] Pareto, W. (1896-1897) Cours D'Economie Politique, Droz, Genève, 1964.

[19] Teles, V. (2004) "The Effects of Macroeconomic Policies on Crime" Economics Bulletin, v.1, n.1. 